\title{
SÉANCE DU 27 NOVEMBRE 1885.
}

PRÉSIDENCE DE M. G. BONNIER, VICE-PRÉSIDENT.

M. Costantin, vice-secrétaire, donne lecture du procès-verbal de la séance du 13 novembre, dont la rédaction est adoptée.

M. le Président, par suite des présentations faites dans la dernière séance, proclame membres de la Société :

MM. Blanc (Édouard), inspecteur adjoint des forèts à Tunis. présenté par MII. Deflers et Malinvaud.

Callamand, bibliothéraire des Facultés de Grenoble, présenté par MM. Bescherelle et Malinvaud.

Coste (l'abbé Hippolyte), professeur à l'institution SaintJoseph, à Villefranche-de-Rouergue, présenté par MM. Loret et Malinvaud.

Fourtau (René), étudiant, rue des Écoles, 12, à Paris, présenté par MM. Amblard et Malinvaud.

Francors, instituteur communal à Porcheux, par Auneuil (0ise), présenté par MM. Malinvaud et Vendryès.

Thierry, directeur du Jardin botanique de Saint-Pierre (Nartinique), présenté par MII. Duval et Malinvaud.

Belzung, agrégé des sciences naturelles, professeur au lycée Charlemagne, présenté par MII. Van Tieghem et Costantin.

M. le Président annonce ensuite deux nouvelles présentations.

M. Venance Payot, dans une lettre adressée à la Société, décrit les effets d'un terrible ouragan qui, s'étant abattu sur Chamonix le 12 novembre, a brisé des milliers de Sapins et de Mélèzes dans la forêt du Lays. Notre confrère, en examinant les arbres renversés, a découvert deux faits tératologiques dont il a été vivement frappé. Le premier est un Mélèze, du moins paraissant tel par le tronc et l'écorce, dont les branches sont celles d'un Sapin. Un peu plus loin, il a vu un second arbre hybride, du moins qu'il a considéré comme tel, représentant un Sapin dans sa partie inférieure jusqu'à 1 mètre de hauteur et un Bouleau dans le reste de la tige el les branches.

M. Malinvaud dit que les phénomènes signalés par II. Pạot sont 
des plus curieux, mais que, quelle que soit l'explication qu'on en donne, il est impossible d'admettre que le second soit le résultat d'une hybridation entre une Gymnosperme et une Angiosperme.

M. Joseph Vallot partage sur ce point l'opinion de M. Malinvaud. Il rapporte qu'il a vu à Cauterets un vieux Sapin brisé à quelques mètres au-dessus du sol et devenu creux à sa partie supérieure ; dans le terreau qui s'y accumulait s'était développé un Sambucus racemosa dont la taille atteignait un mètre. Les faits observés par I. Payot étaient probablement dus à une cause analogue.

M. G. Camus fait à la Société la communication suivante :

\section{SUR UNE VARIÉté NOUVElle DE POLYGaLA CALCAREA, par M. G. CAMUS.}

On sait que le Polygala calcarea de Schultz se présente sous 4 formes:

$1^{\circ}$ Polygala calcarea à fleurs bleues (type).

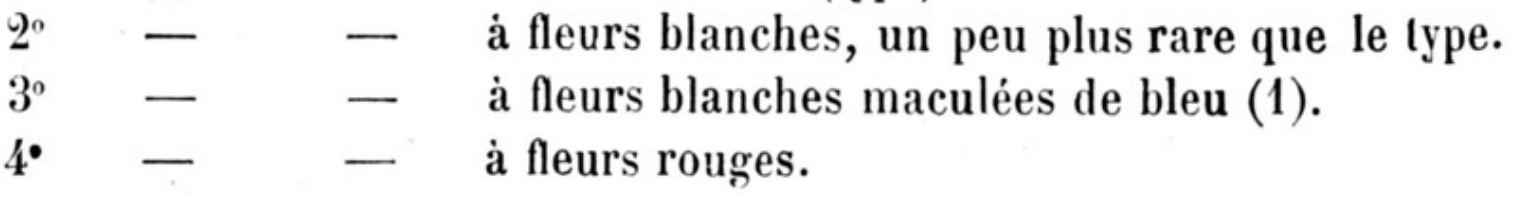

Je comprends ces 4 formes dans la variété pour laquelle je propose le nom de $P$. calcarea var. erecta par opposition à une seconde variété que je nomme $P$. calcarea var. prostrata.

J'ai trouvé cette dernière variété à Champagne (Seine-et-0ise), sur le Montrognon, où elle est gazonnante et abondante, mais circonscrite sur une pelouse rase, très aride, où ne poussent que le Thesium et le Serpolet. Ses caractères sont d'avoir des racines subligneuses, des tiges tortueuses à la base et moins grandes que dans la variété erecta. Les feuilles radicales sont détruites de bonne heure, ce qui, joint à la nutation des types, donne à la plante un port particulier. Les fleurs sont roses, assez nombreuses et réunies en épis très serrés.

M. Rouy fait à la Société la communication suivante :

SUR L'AIRE GÉOGRAPHIQUE DE L'ABJES PINSAPO Boiss. EN ESPAGNE, par M. G. ROUY.

A l'issue de notre dernière séance,j'entretins notre honorable président des doutes que j'avais relativement à la présence de l'Abies Pinsapo

(1) Cette forme ne me paraìt pas être la transition de la première forme à la deuxième, mais ètre issue de leur croisement, car je ne l'ai jamais vue sans ses parents présumés. 


\section{$2 \mathrm{BHL}$ Biodiversity Heritage Library}

1885. "Séance Du 27 Novembre 1885." Bulletin de la Société botanique de France 32, 365-366. https://doi.org/10.1080/00378941.1885.10828369.

View This Item Online: https://www.biodiversitylibrary.org/item/8654

DOI: https://doi.org/10.1080/00378941.1885.10828369

Permalink: https://www.biodiversitylibrary.org/partpdf/158958

\section{Holding Institution}

Missouri Botanical Garden, Peter H. Raven Library

\section{Sponsored by}

Missouri Botanical Garden

\section{Copyright \& Reuse}

Copyright Status: Public domain. The BHL considers that this work is no longer under copyright protection.

This document was created from content at the Biodiversity Heritage Library, the world's largest open access digital library for biodiversity literature and archives. Visit BHL at https://www.biodiversitylibrary.org. 